\title{
Clube da Química: uma abordagem Ciência-Tecnologia-Sociedade no uso de trechos de filme como recurso metodológico para o Ensino de Química.
}

\author{
Samuel Vitor da Silva (PIBID-IFPI)- \\ Instituto Federal do Piauí- IFPI (Campus Picos) - samuelvictorfs95@gmail.com \\ Maura Almeida da Silva (PIBID-IFPI) \\ Instituto Federal do Piauí- IFPI (Campus Picos)- maura_almeida_sal@hotmail.com \\ Francisca da Chagas Alves da Silva \\ Instituto Federal do Piauí- IFPI (Campus Picos)- fran-arosio@hotmail.com \\ Jorge Roberto Assunção Cardoso (COORDENADOR DO PIBID-PQ) \\ Instituto Federal do Piauí- IFPI (Campus Picos) - iracardoso@ifpi.edu.br
}

\section{Resumo}

O presente trabalho tem o objetivo de analisar se o uso de trechos de filmes como recurso didático na abordagem CTS, sobre o conteúdo de "Radioatividade" proporciona aprendizagem para os discentes. A pesquisa foi efetuada no Instituto Federal do Piauí-Campus Picos, localizado no município de Picos-PI, a partir do subprojeto PIBID e o projeto de extensão Clube da Química. Logo de inicio, foi contextualizado o conteúdo de Radioatividade inserido trechos de filmes com "Césio 137- O pesadelo de Goiânia" e "K19", por fim, foi realizado um questionário para verificar a obtenção de aprendizagem pelos discentes. Assim, os resultados demostraram que a abordagem CTS com o uso de trechos de filme adquiriu aspectos positivos para a construção do conhecimento científico.

Palavras chaves- Trechos de filmes, Abordagem CTS, Clube da Química.

\section{Introdução}

O Clube da Química é um projeto que envolve atividades capazes de edificar a conhecimento cientifico dos discentes, através de recursos lúdicos que possibilita a construção aprendizagem. Desse modo, a ideia do clube é promove a formação crítica dos alunos, ou seja, contribuído para formar cidadão participativo e colaborativo diante das questões que abranjam os contextos sociais.

Segundo OLIVEIRA et al (2016) "a necessidade de abordar os conteúdos específicos da disciplina atrelados a um contexto de aplicação, enfatizando a função social de cada assunto e com isso, aproximar esses temas da realidade dos estudantes". Desse modo, o enfoco Ciência-Tecnologia-Sociedade-CTS possibilita uma abordagem contextualizada do conteúdo de química, colaborado na formação crítica do cidadão.

A abordagem do conteúdo com recursos audiovisual proporciona a construção da aprendizagem para os alunos, pelo fato de envolve à temática de forma motivadora e que o questione sobre o contexto. Porém, no Ensino Médio, é retratado que a maior parte dos docentes se acomoda no ensino tradicional, apropriando uma aprendizagem desestimulante para os discentes e intitulando uma visão distorcida da Química. 
De acordo com (LEAL, 2009), pela restrição de tempo do hábito escolar, o uso de partes de filmes, tem uma potencialidade positivo, pois se vincula na compreensão dos aspectos científicos e promove na construção do conhecimento. Contudo, os trechos de filmes possibilitam uma propagação do conhecimento científico em um pequeno intervalo de tempo, logo, a articulação e o planejamento são fundamentais para a realização da prática do docente.

O presente trabalho tem como objetivo de analisar se o uso de trechos de filmes como recurso didático sobre o conteúdo de "Radioatividade" promove aprendizagem para os discentes.

\section{Procedimento metodológico}

A pesquisa foi realizada no Instituto Federal de Educação, Ciência e Tecnologia do Piauí- Campus Picos, localizado no município de Picos-PI, com o apoio do subprojeto PIBID e pelo projeto de extensão Clube da Química, com os estudantes do $1^{\circ}$ e $2^{\circ}$ ano do Ensino Médio (total de 15 alunos), durante o primeiro semestre do ano letivo de 2017. A natureza da pesquisa foi de análise qualitativa e investigativa, com a finalidade de analisarmos aprendizagem dos discentes.

No primeiro momento, foram ministradas aulas em uma perspectiva contextualizada, onde inicialmente problematizando conteúdo de Radioatividade com leitura texto, em prol de organizar o conhecimento e em seguida aplicamos o conhecimento para aprofundarmos no conteúdo. É nesse critério que rebuscamos a abordagem CTS, envolvendo os discentes em situações-problemas, levando-os a discussão sobre o tema.

Assim, forma utilizados trechos de filme como "Césio 137- O pesadelo de Goiânia" e "K19" ao decorre da aula, com o intuito de enriquecer ainda mais os conhecimentos diante o conteúdo. No segundo momento, após de aborda a temática, constituiu um questionário audiovisual para analisa se uso dos trechos de filmes contribuíram para a aprendizagem dos discentes.

\section{Resultados e discussões}

Durante a aula pode-se diagnosticar que os discentes eram providos de conhecimentos prévios do conteúdo apresentado. Logo, a tomada de decisão dos mesmos sobre os trechos de filmes gerou um momento de debate, vinculando as situações 
problemáticas cinematográficas em contra posto com o senso crítico dos alunos, assim estimulando e edificando para a formação do conhecimento científico.

Ao analisarmos, podemos perceber que a inserção de trechos de filmes durante a aula proporcionou 13,3\% rejeição dos estudantes por esse tipo de metodologia. O aluno A descreveu "sou acostumada aulas expositivas, esse método não contribuiu muito para minha aprendizagem [...]”.

Por outro lado, o recurso metodológico proporcionou 86,7\% para aprendizagem dos discentes. O aluno B descreveu "foi bastante construtivo na minha aprendizagem, pois consegui assimilar o conteúdo com o contexto retratado no filme e assim me motivou a questionar sobre o impacto da Química na vida da sociedade”. Dessa forma, o docente deve se centrar em investigar como está sendo à aprendizagem dos alunos, logo, incrementado metodologias capazes de estimular e motiva-los, assim contribuindo para formação dos conhecimentos científicos.

Gráfico: análise da aprendizagem dos discentes pelo uso de trechos de filme.

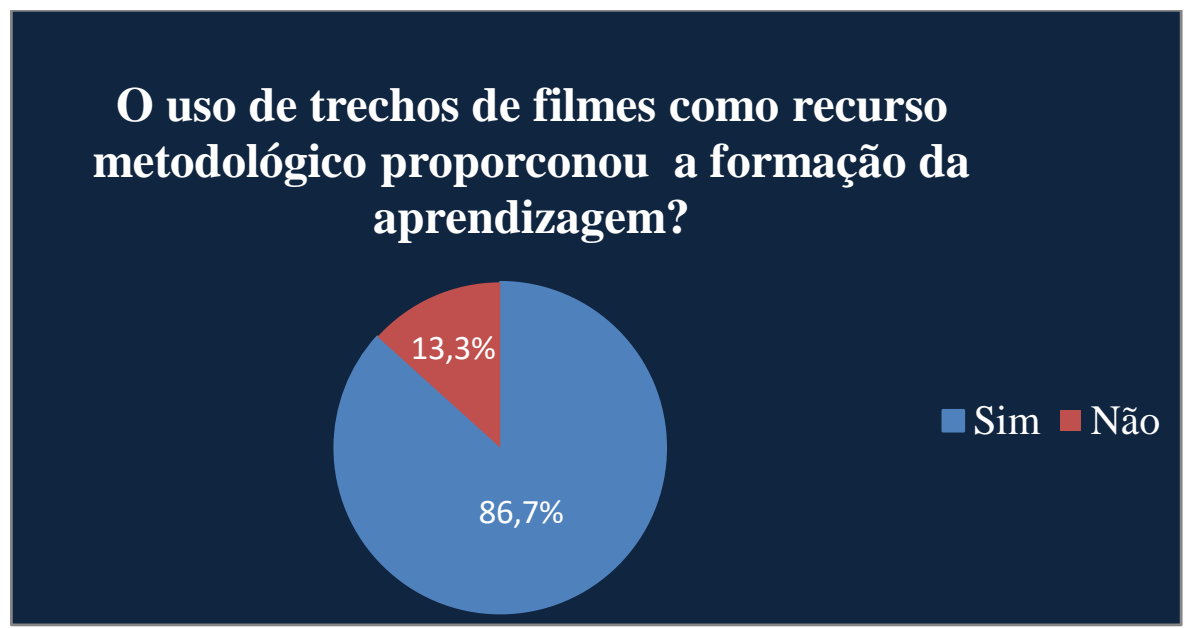

Fonte: Autoria Própria

Nessa perspectiva, os trechos de filmes quando abordado em enfoco CTS, facilita o processo de aprendizagem para os discentes, por atuar como potencial educativo para o dialogo a partir de temas geradores. Portanto, "experienciar os recursos midiáticos como ferramentas pedagógicas pode viabilizar ao discente a oportunidade de investigar e refletir aprendizados pertinentes às variadas temáticas que o cerca”. (SILVA, 2010).

\section{Considerações finais}

É visto que, a abordagem CTS com o uso de trechos de filme adquiriram aspectos positivos para a construção do conhecimento científico e na forma da aprendizagem para os discentes. Assim, foram-se alcançadas as perspectivas que o Clube da Química almeja, 
pois esse projeto está em processo de se expandir está para escolas públicas onde a inserção do subprojeto PIBID.

Agradecimentos: Ao programa Institucional de Bolsa de Iniciação à DocênciaPIBID, ao IFPI e à CAPES.

\section{Referências}

LEAL, M. C. Didática da Química: fundamentos e práticas para o Ensino Médio. Belo Horizonte: Dimensão, 2009.

OLIVEIRA, S.; GUIMARÃES, O. M.; LORENZETTI, L. O Ensino de Química e a Qualidade do Ar Interior: Análise de uma Proposta de Abordagem Temática com Enfoque CTS. Revista Brasileira de Pesquisa em Educação em Ciências-RBPEC. v 16. n 3. pp. 521-553. dezembro 2016. Disponível em: https://seer.ufmg.br/index.php/rbpec/article/view/2723/2790. Acesso em: 14 de junho 2017

SILVA, R. V.; OLIVEIRA, E. M. As possibilidades do uso do vídeo como recursos de aprendizagem em salas de aulas do $5^{\circ}$ ano. In: ENCONTRO DE PESQUISA EM EDUCAÇÃO DE ALAGOAS, 5., 2010, Alagoas. Anais eletrônicos... Alagoas: UFAL, 2010. Disponível em: http://www.pucrs.br/famat/viali/tic_literatura/artigos/videos/Pereira_Oliveira.pdf. Acesso em: 15 de junho de 2017. 